\section{PTU-030 PALLIATIVE CARE IN LIVER CIRRHOSIS: ARE WE EFFECTIVE IN PROVIDING APPROPRIATE END OF LIFE CARE?}

Simon Phillpotts*, Cameron Green, Krishna Shah, Jason Lo, Sushma Saksena. Royal London Hospital. Barts Health NHS Trust, UK

\subsection{6/gutjnl-2019-BSGAbstracts.239}

Introduction Liver disease accounts for $2 \%$ of deaths in the $\mathrm{UK}$ and is the third commonest cause of premature death. The GMC and Gold standards framework recommend identifying and providing support to patients in the final 12 months of life. A British study from 2017 showed good results after creating a dedicated Liver MDT, discussing cases that were identified as having a poor prognosis ${ }^{1}$.

Aim To assess the palliative care input and levels of inpatient care for patients who died with a diagnosis of liver cirrhosis.

Method Retrospective audit of all in hospital deaths with a coded diagnosis of cirrhosis, from September 2016-2017 at a large Tertiary Referral Centre in London.

\begin{tabular}{|c|c|c|c|c|c|}
\hline \multicolumn{6}{|c|}{ Demographics } \\
\hline \multirow{5}{*}{$\begin{array}{l}\text { Total } \\
\text { patients }\end{array}$} & 53 & Child Pugh & A 12 & Aetiology & ALD 33 \\
\hline & (M30, & & B 20 & & HCV 8 \\
\hline & F23) & & C 21 & & $\mathrm{HBC} 2$ \\
\hline & & & & & NASH 6 \\
\hline & & & & & AlH 1 \\
\hline Age & $\begin{array}{l}63 y(33- \\
88 y)\end{array}$ & $\mathrm{HCC}$ & 8 & & \\
\hline \multicolumn{6}{|c|}{ Referral to palliative care } \\
\hline \multirow[t]{4}{*}{ Referred } & Y 18 & Average time & 6.5 days & $\mathrm{N}^{\circ}$ referred & 3 \\
\hline & N 27 & of referral prior & & prior to final & \\
\hline & Unknown & to death & & admission & \\
\hline & 8 & & & & \\
\hline \multicolumn{6}{|c|}{ Final 12 month of life } \\
\hline \multirow{4}{*}{$\begin{array}{l}\text { Known to } \\
\text { Hepatology }\end{array}$} & $12 \mathrm{~m}$ & $28(53 \%)$ & & Referred for & 4 \\
\hline & before & & & OLTx & \\
\hline & death & & & assessment & \\
\hline & $\begin{array}{l}\text { At final } \\
\text { admission }\end{array}$ & $40(75 \%)$ & & & \\
\hline \multicolumn{6}{|c|}{ Poor prognostic features at final admission ${ }^{1}$} \\
\hline $0=7$ & \multicolumn{2}{|c|}{$3=6$} & $\mathrm{CTP} C=21$ & \multicolumn{2}{|c|}{ Ongoing EtOH $=28$} \\
\hline $1=20$ & \multicolumn{2}{|c|}{$4=1$} & PS $3-4=27$ & \multicolumn{2}{|c|}{ Not for OLTX $=2$} \\
\hline \multicolumn{3}{|l|}{$2=19$} & & \multicolumn{2}{|c|}{ Repeat admissions $=4$} \\
\hline \multicolumn{6}{|c|}{ Level 2/3 care } \\
\hline Admissions & $26(49 \%)$ & Average stay & 6.1 days & Died on ITU & 18 \\
\hline
\end{tabular}

Results Three quarters of patients were known to the Hepatology service yet only a third were referred to palliative care service; median time of referral was 6.5 days (1-523) before death. The criteria used by Hudson to identify patients suitable for palliative care input identified only 7 (13\%) patients in this retrospective cohort. Nearly half the patients were admitted to level $2 / 3$ care in their last hospital admission before death.

Conclusions This audit highlights a number of areas for improvement in provision of palliative care for patients with liver cirrhosis. These include, better prognostic tools to identify patients that would benefit from best supportive care; applying these tools at an earlier point in patient's care; and considering whether higher levels of care are appropriate.

Solutions include dedicated MDTs and improved communication of decision making and advance care planning, with the objective of ensuring patients receive appropriate supportive care, whilst providing support and funding for all health care professionals involved.

\section{REFERENCES}

1. Hudson B et.al. Integration of palliative and supportive care in the management of advanced liver disease: development and evaluation of a prognostic screening tool and supportive care intervention. Frontline Gastroenterology 2017;8:45-52

\section{PTU-031 DRUG INDUCED LIVER INJURY AMONG PATIENTS WITH MULTIPLE SCLEROSIS TREATED WITH ALEMTUZUMAB- A SINGLE-CENTRE EXPERIENCE}

${ }^{1}$ Liane Rabinowich*, ${ }^{2}$ Eli Silber, ${ }^{2}$ Peter Brex, ${ }^{3}$ Deborah Clark, ${ }^{2}$ Gosia Kuran, ${ }^{3}$ Sara Sawieres, ${ }^{1}$ Michael A Heneghan. 'Institute of Liver Studies, king's College Hospital, London, UK; ${ }^{2}$ Department of Neurology, King's College Hospital, London, UK; ${ }^{3}$ Pharmacy Department, King's College Hospital, London, UK

\subsection{6/gutjnl-2019-BSGAbstracts.240}

Backround and aims Alemtuzumab (Lemtrada) is a humanized monoclonal anti-CD52 antibody approved for the treatment of patients with relapsing-remitting multiple sclerosis (RRMS). Current information regarding drug induced liver injury (DILI) during treatment is available from small cohorts and case reports. Our aim was investigate the prevalence of DILI among patients with RRMS treated with Alemtuzumab.

Methods Retrospective analysis of epidemiological, clinical and laboratory data of all patients with RRMS treated with Alemtuzumab in King's College Hospital between December 2014 to August 2018.

Results 94 RRMS patients received Alemtuzumab. The average age of the patients was 36 years (range 18-55) and most patients were female (71.3\%); 56 patients received 2 annual treatment courses. Deranged liver enzymes developed during the 5 days of admission for Alemtuzumab treatment in 25 patients (26.5\%). Among them, the average age was 37 (range 18-53) and the majority were female $(68 \%)$. The pattern of elevated liver enzymes was cholestatic (elevated GGT) in 11 patients, hepatocellular (elevated AST) in 6 patients and mixed in 6 patients. Among 3 patients with elevated bilirubin, 2 involved an isolated increase in bilirubin. The degree of AST elevation was mild $(<\mathrm{X} 3 \mathrm{ULN})$ in 9 patients, between $\mathrm{X} 3-$ 5 ULN in one patient and between X5-X10ULN in 2 patients. GGT elevation was also largely mild, <X3ULN in 13 patients, between X3-X5ULN in 3 patients and severe (>X10ULN) in one patient. Among all patients with available post treatment data liver functions returned to baseline. Patients with markedly elevated liver enzymes did not receive a second course of Alemtuzumab. Among 15 patients that received two annual courses, elevated liver enzymes were observed only during the first course in 7 patients and only during the second course in 4 patients. Four patients received 2 treatment courses, all with a mild degree of liver enzyme elevation.

Conclusions Liver enzyme elevation was observed in $26.5 \%$ of RRMS patients treated with Alemtuzumab. As the exact mechanism of this form of DILI is not well established, monitoring during Alemtuzumab treatment is important and re-challenging should be decided individually. 